\title{
Reorganização Familiar e Rede Social de Apoio Pós-homicídio Juvenil ${ }^{1}$
}

\author{
Daniela Fontoura Domingues ${ }^{2}$ \\ Maria Auxiliadora Dessen \\ Universidade de Brasília
}

\begin{abstract}
RESUMO - A morte violenta de jovens provoca mudanças no cotidiano das famílias e nas comunidades, particularmente nos modos de organização dos sobreviventes. Este estudo buscou investigar as transformações nos sentimentos, nas relações sociais e na rede social de apoio de oito famílias que perderam jovens vitimados por homicídio no Distrito Federal. Participaram da pesquisa mães e irmãos destes jovens, que responderam a um questionário de caracterização do sistema familiar e a uma entrevista semiestruturada. Os relatos, submetidos à análise qualitativa, apontaram sentimentos de desespero, dor, culpa, revolta e medo. O episódio alterou o funcionamento familiar, provocando desorganização nas relações conjugais e parentais. Os resultados indicam a necessidade de fortalecer a rede social dessas famílias e de investir em políticas públicas.
\end{abstract}

Palavras-chave: família, violência, homicídio juvenil, luto, rede social de apoio

\section{Family Reorganization and Social Support Network after a Juvenile Homicide}

\begin{abstract}
The violent death of young people causes changes in the everyday life of families and communities, particularly in the survivors' ways of organization. This study aimed to investigate the alterations in the emotional and relational aspects as well as in the social support network of eight families who lost young relatives, victims of homicide in the Federal District. The victims' mothers and siblings participated in the research answering a questionnaire about the family system and a semistructured interview. The reports were submitted to qualitative analysis and showed feelings of despair, pain, guilt, anger, and fear. The episode changed the family functioning, causing disruption to marital and parental relationships. The results indicate the necessity of strengthening the social support network and investing in public policies.
\end{abstract}

Keywords: family, violence, juvenile homicide, bereavement, support network

A morte de jovens, vítimas de homicídio, é um problema grave e complexo que afeta milhares de famílias todos os anos, conforme vem sendo relatado pela literatura nacional (Cano \& Ribeiro, 2007) e estrangeira (Salloum \& Rynearson, 2006; Spungen, 1998; Temple, 1997). Diversos fatores contribuem para os elevados índices de homicídios no Brasil. Entre eles, merece destaque a desigualdade na distribuição de renda, a falta de oportunidades de emprego e moradia para as camadas mais desfavorecidas da população e, sobretudo, a escassez de investimentos no setor educacional (Waiselfisz, 2010). Embora diversas iniciativas na área da saúde e da educação tenham favorecido o decréscimo da mortalidade infantil nas últimas décadas, dados sobre os óbitos nesta faixa etária e no período da juventude não têm acompanhado essa tendência (Peres, Cardia, \& Santos, 2006).

Para melhor compreender o fenômeno, Elgar e Aitken (2010) realizaram um estudo em 33 nações de diferentes continentes e com características socioeconômicas distintas. Os resultados mostraram que sociedades com grandes discrepâncias de rendimentos e baixo nível de confiança interpessoal são as que dispõem de um aparato social menos eficaz na prevenção dos delitos e, por conseguinte, na construção de

1 Apoio: CAPES

2 Endereço para correspondência: Departamento de Psicologia Escolar e do Desenvolvimento, Instituto de Psicologia, Universidade de Brasília, Campus Universitário Darcy Ribeiro, Asa Norte. Brasília, DF. CEP 70.910-900.E-mail: danydom61@gmail.com comunidades seguras. Rompimentos nas relações familiares, alterações em crenças e valores e atrativos financeiros para ações na marginalidade são, também, fatores que potencializam ambientes adversos e colaboram para as situações de violência (Barber-Madden \& Saber, 2010).

Os motivos relacionados aos homicídios variam desde questões individuais e intrapessoais até circunstanciais e contextuais (Vasconcelos \& Costa, 2005). Todos eles constituem fatores de risco e de proteção que embasam as relações sociais e atuam na determinação desse tipo de evento, bem como na dinâmica da vitimização (Peres, 2007). Os homicídios atingem, preferencialmente, indivíduos do sexo masculino que estão entre a fase da adolescência e os 30 anos de idade (Cano \& Ribeiro, 2007).

Em virtude da precocidade das mortes, as expectativas nutridas pelos genitores em relação à sua prole sofrem alterações, já que é presumido que venham a falecer antes dos seus filhos (Kovács, 1992). Além disso, por tratar-se de um episódio que, na maioria das vezes, acontece de forma inesperada, inviabiliza a preparação para a perda. A experiência do luto antecipatório é suprimida, em tais episódios, de modo que os familiares e amigos deixam de ter a oportunidade da despedida, como acontece com as doenças graves, de prognóstico reservado (Kovács, 1992; Miller, 2009). Além disso, a associação entre violência e imprevisibilidade gera reações de choque, perplexidade e intenso estresse às pessoas envolvidas (Currier \& Neimeyer, 2006), levando-as a recorrer a estratégias de negação, dis- 
sociação e distanciamento dos episódios (Raphael, Stevens, \& Dunsmore, 2006).

Os homicídios juvenis constituem, portanto, acontecimentos não normativos capazes de ocasionar comportamentos disfuncionais (Walsh \& McGoldrick, 2004). Por serem eventos potencialmente danosos, expressões de mágoa e tristeza são comuns e, frequentemente, estão entremeadas por raiva, medo e culpa (Shear, Gorscak, \& Simon, 2006). Sobre este último sentimento, Raphael et al. (2006) destacam que manifestações autoacusatórias ganham intensidade por derivarem de relações ambivalentes estabelecidas entre os sobreviventes e a vítima, em época anterior ao seu falecimento. Portanto, aspectos antecedentes e subsequentes às mortes exercem influência na maneira como os familiares vivenciam e enfrentam a perda.

A unidade familiar, por sua vez, sofre uma transformação ampla e geral que abrange desde a sua dinâmica e funcionamento até os modos de organização e estilos de comunicação (Domingues, Villas Boas, \& Dessen, 2011; Walsh, 2007). A redefinição de papéis é um dos aspectos mais evidentes nesse processo, pois os membros do sistema parental, na tentativa de evitar sofrimento adicional aos outros filhos, costumam assumir uma postura excessivamente protetora para desviar a atenção sobre a perda, negligenciando o próprio desgosto e pesar (Spungen, 1998). Além disso, óbitos por homicídio envolvem instâncias públicas, como órgãos de justiça e polícia, que têm por objetivo investigar, esclarecer e punir os culpados. O aparato legal, em contrapartida, subtrai da família a possibilidade de resguardo e privacidade (Salloum \& Rynearson, 2006).

As repercussões de um homicídio têm implicações não somente para os membros da família, mas também para a comunidade, pois, ao mesmo tempo em que esta pode reproduzir as situações de violência, pode fornecer suporte por intermédio da rede social de apoio. As pessoas em luto são tanto receptoras das ações de sua rede, como atuam para mudá-la, construindo novos vínculos ou mesmo fortalecendo e resgatando antigos contatos (Schaefer \& Moss, 2007). Uma participação ativa do indivíduo na comunidade, por exemplo, o auxilia a lidar com as situações adversas, na medida em que aciona recursos disponíveis na vizinhança (Andrade \& Vaitsman, 2002).

A rede social constitui "um sistema que oferece apoio instrumental e emocional à pessoa, em suas diferentes necessidades" (Dessen \& Braz, 2000, p. 221), além de estimular a sensação de bem-estar dos indivíduos, reforçando a autoestima e os laços afetivos (Mayer, 2002). Ela é formada com base nas relações significativas estabelecidas entre parceiros, familiares, vizinhos, amigos, colegas de trabalho (Sluzki, 1997), podendo até incluir representantes escolares, líderes comunitários e o próprio sistema de saúde (Raphael et al., 2006).

Apesar da diversidade de sua configuração, Pressman e Bonanno (2007) destacam que há distinção entre o papel dos familiares e dos amigos como parte da rede social de apoio em situações de luto. Para os autores, as relações estabelecidas no meio familiar resultam de uma história comum entre os membros e, por esta razão, adquirem um significado e uma função específica. Assim, a estrutura da rede social de apoio e suas finalidades variam de acordo com o contexto e com o tempo histórico (Dessen \& Braz, 2000) e, dependendo do local e do ambiente, a escassez de suporte pode contribuir para o aumento da fragilidade do grupo familiar.

Quando não há uma rede consistente, sentimentos de solidão e desinteresse pela vida tendem a prevalecer (Mayer, 2002), desencadeando inúmeros prejuízos às pessoas que enfrentam episódios inesperados e traumáticos. As migrações involuntárias, decorrentes de ameaças e represálias, por exemplo, tornam a família mais suscetível a rupturas e a perturbações (Mota, Franco, \& Motta, 1999). Essas mudanças representam uma violação aos direitos humanos e têm repercussões negativas na qualidade de vida dos sobreviventes (Builes, Arias, \& Minayo, 2008).

Sendo assim, a rede social de apoio, em casos de homicídio, deve ser capaz de oferecer assistência legal, psicológica e financeira (Viano, 2007), tendo em vista que os familiares das vítimas precisam lidar com o acontecimento súbito e com o trauma provocado pela violência do ato (Asaro, 2001). De acordo com Salloum e Rynearson (2006), ainda que trabalhos sobre o apoio psicológico de profissionais sejam incipientes, é inegável o efeito positivo das intervenções grupais e familiares direcionadas aos enlutados. Dentre elas, tais autores destacam o estímulo à comunicação franca e aberta entre os membros, o cuidado mútuo e, sobretudo, o fortalecimento da unidade familiar.

Portanto, a recomposição familiar que é essencial para a readaptação da família à sociedade, depende não apenas de fatores internos desses indivíduos, tais como a estrutura psicológica, o histórico de perdas anteriores e suas próprias crenças, mas também de fatores externos que incluem as circunstâncias do evento, a rede social de apoio e os recursos da comunidade (Bromberg, 1996). Dada a importância do tema, particularmente no Brasil, este estudo tem por objetivo investigar as mudanças individuais, familiares e sociais e o papel da rede social de apoio de famílias que tiveram um jovem vitimado por homicídio por arma de fogo, nos primeiros 12 meses de luto.

\section{Método}

\section{Participantes}

Participaram do estudo oito famílias. Cada uma delas contou com a adesão de duas pessoas: uma do sistema parental (mãe: $n=8$ ) e outra do fraternal (irmão: $n=5$ ). Em duas dessas famílias, o jovem falecido era o único filho e, em outra, o irmão não pode participar. As famílias eram de nível socioeconômico baixo, procedentes de regiões periféricas do Distrito Federal, e estavam vivenciando a perda de um jovem (filho/irmão) vitimado por homicídio por arma de fogo. Todas se encontravam em um período de luto compreendido entre os primeiros 30 dias e os 12 meses após o episódio.

Os jovens vitimados $(n=8)$ tinham em média 18,7 anos de idade, por ocasião do homicídio. A maior parte deles era do gênero masculino $(n=7)$, de raça parda e não havia completado o Ensino Fundamental. Dois não tinham ocupação; os demais frequentavam a escola ou desenvolviam algum tipo de atividade laboral, como a realização de pequenos "bisca- 
tes". Dos oito jovens, apenas um havia deixado dependentes (filhos), sendo esta a única vítima do gênero feminino.

\section{Procedimentos para Coleta de Dados}

Em razão das circunstâncias ambientais implicadas nos homicídios, tais como tráfico de drogas e disputa entre gangues, algumas famílias do estudo foram indicadas por pessoas que pertenciam a organizações não governamentais (ONGs) que atuavam na prevenção da violência no Distrito Federal. Outras foram selecionadas por profissionais da área do Direito e da Psicologia compondo, portanto, uma amostra por conveniência. Das 16 famílias convidadas, apenas oito aderiram à pesquisa. Dentre os motivos alegados para a recusa estava a falta de condições emocionais e psicológicas e o receio de represálias, em virtude de alguns perpetradores dos homicídios não terem sido encarcerados até a época da realização do estudo.

A coleta de dados ocorreu na residência dos participantes, após aprovação do Comitê de Ética da Universidade de Brasília (UnB), cujo projeto foi inscrito neste Comitê sob o número 179/2008. O trabalho consistiu na aplicação de dois instrumentos: a) o Questionário de Caracterização do Sistema Familiar (Dessen, 2009), respondido pelas mães, incluindo perguntas sobre idade, nível de escolaridade e ocupação dos participantes, além de questões específicas a respeito das relações familiares e de aspectos de infraestrutura e recursos disponíveis aos moradores das comunidades; b) um roteiro de entrevista semiestruturada, respondido pelas mães e irmãos, a respeito das circunstâncias dos homicídios, do impacto da perda na organização familiar, da rede social de apoio, dos padrões de comunicação na família, bem como dos valores e expectativas dos familiares para o futuro.

\section{Análise de Dados}

Os dados do questionário de caracterização do sistema familiar foram tabulados, e as entrevistas gravadas em áudio - com duração média de duas horas cada - foram transcritas na íntegra, totalizando 13 entrevistas e 26 horas de gravação. O material foi identificado e digitalizado para viabilizar o processo de escuta e transcrição. Todas as verbalizações foram submetidas à técnica de Análise de Conteúdo (Bardin, 1977) e, em seguida, o material passou por uma categorização, conforme os passos de construção do sistema de categorias proposto por Dessen e Cerqueira-Silva (2009). Esse procedimento envolveu quatro etapas, a saber: a) seleção e exploração do material (pré-análise); b) codificação; c) agrupamento e reagrupamento de temas; e d) definição das categorias empíricas (tratamento, inferência e interpretação dos resultados).

\section{Resultados}

Para a análise dos resultados, as oito famílias do estudo (F1, F2, F3, F4, F5, F6, F7 e F8) foram divididas em dois grupos: Grupo A e Grupo B. O Grupo A era composto por famílias (F3, F4, F5, F7 e F8) cujos jovens apresentavam comportamentos transgressores antes dos homicídios. No Grupo B (F1, F2 e F6), por sua vez, os jovens não tinham antecedentes dessa natureza, segundo declarações dos familiares. Foram considerados comportamentos transgressores o envolvimento em furtos, roubos, cumprimento de medida socioeducativa ou prisão, tráfico de entorpecentes, uso/abuso de álcool e de outras drogas.

Além dos comportamentos antecedentes das vítimas, os participantes ressaltaram a violência em suas regiões de moradia como aspecto relacionado às mortes. Outro dado relevante referiu-se à experiência anterior de perda - de indivíduo também jovem, da mesma família e em circunstâncias semelhantes. Três famílias do estudo (F1, F2 e F7), de ambos os grupos, informaram ter enfrentado, também, a morte por homicídio de um sobrinho (F1 e F2) e de um outro filho (F7).

As três grandes categorias reveladas no estudo foram: sentimentos em relação à perda, mudanças familiares e sociais e rede social de apoio. Todas as categorias deram origem a subcategorias, descritas e ilustradas, a seguir, de acordo com as verbalizações dos entrevistados. As falas estão aqui identificadas pela letra M (mãe) ou I (irmão) e pelo número da família às quais pertenciam: 1, 2, 3, 4, 5, 6, 7 ou 8 .

\section{Sentimentos em Relação à Perda}

Com base no processo de categorização, os sentimentos expressos pelos participantes foram agrupados em sete subcategorias: descontrole/desespero, depressão/vontade de morrer, dor/sofrimento, saudade/falta, revolta/vingança, culpa e medo. A primeira delas - descontrole/desespero - foi caracterizada pela intensidade e exacerbação dos afetos, cujas verbalizações foram expressas por três famílias (F1, F2, F4), duas das quais do Grupo B, conforme exemplos. "Eu entrei em desespero... Eu tava em pânico, tava em desespero. Eu pensava que eu ia enlouquecer. Às vezes eu penso que tô ficando louca" (M1). "A gente ficou muito abalado" (M2). "Eu fiquei descontrolada" (M4).

A depressão/vontade de morrer foi relatada por quatro famílias (F1, F3, F5, F8):

\footnotetext{
"Tô vivendo assim, tanto faz como tanto fez." (M1)

"Eu tomei até um remédio pra mim morrer." (M3)

"Eu pensei até em me matar. Comprei gilete, mas eu sou uma pessoa muito covarde, eu não tenho coragem de fazer isso comigo." (M5)

"Não sinto vontade mais, assim, de nada; não tenho vontade de nada." (M8)
}

Já, a terceira subcategoria, dor/sofrimento, foi mencionada por seis famílias (F1, F2, F3, F4, F6, F8), independentemente da história de vida dos jovens ou de outras características, de acordo com as falas:

\footnotetext{
"O momento que eu mais sofro é quando tô só." (M1)

"Eu sofri tanto... eu sofri tanto... eu não sei o que será de mim.” (M3)

"É uma coisa medonha, uma coisa duedera." (M4)

"Tô sentindo assim, só dor, muita dor mesmo." (M8)
} 
A quarta subcategoria, saudade/falta do jovem vitimado, foi também expressa por seis famílias (F1, F2, F4, F6, F7 e F8), como exemplificado pelas seguintes verbalizações:

\footnotetext{
"No lugar da dor, fica só a saudade. É difícil demais pra mim." (M2)

"Saudade que é imensa... você não pode olhar pra um canto, não pode olhar pra outro... parece ele, o jeitinho dele." (M4)

"Saudade é olhar pro mundo e saber que ele não existe mais comigo." (M1)

"Aprender a conviver sem a pessoa aqui, sentir a falta do seu ente querido aqui dentro de casa. Como viver sem ele, viver sem pessoa?" (M7)
}

As sensações de revolta/vingança foram sinalizadas por três famílias do estudo (F1, F5 e F7). Entre elas estava uma família cuja genitora se sentiu criticada por pessoas de sua rede social, em virtude do comportamento pregresso do jovem (F5). "Eu acho que essas pessoas que viram eu passar por tudo e que falaram mal dele, eu fico achando que elas têm que passar também, pelas mesmas coisas" (M5). As outras duas famílias comentaram sobre o perpetrador do homicídio que se encontrava em liberdade, como mostra a fala de um dos participantes:

"Isso que eu fico mais revoltado! Mata os outros e fica andando assim na rua, na maior cara de pau! Os amigos dele falaram que ele (autor do homicídio) fica é bebendo e... rindo. Quando a gente perde um irmão, a gente só tem o pensamento de vingar." (I7)

A culpa (F4 e F5) foi relatada em dois contextos distintos. Em um deles, a genitora alegou que além de se sentir culpada, os familiares também a culpavam: "Elas (irmãs) me culpam" (M4). A outra família (F5), cuja morte do jovem havia sido desejada pela genitora em virtude do comprometimento do filho em ações delituosas, expressou recriminações autoacusatórias: "Eu começo a me culpar por muita coisa que aconteceu” (M5).

O sentimento de medo, última subcategoria, foi manifestado de diversas maneiras pelas famílias de ambos os grupos, tendo como origem a ameaça à integridade física dos familiares. O medo de morrer, isto é, de perder a vida de forma violenta e de modo semelhante ao jovem vitimado, foi expresso unicamente pelos irmãos (I1, I2, I7), conforme segue:

\footnotetext{
"Medo de eu morrer, penso que vai acontecer o mesmo comigo." (I1)

"Aí eu tenho medo de ir e quando for mais tarde eu não "tá" aqui, entendeu? Igual meu irmão, ele só foi fazer um lanche e não voltou” (I2).

"Eu posso estar no momento errado e morrer de graça... ',

Já o temor dos familiares (F1, F2, F7 e F8), de perderem outras pessoas da família ou ficarem sós, foi descrito tanto pelas genitoras quanto pelos irmãos:

\footnotetext{
“Eu tenho medo de perder ela (filha).” (M1)
}

"A gente não confia inteiramente, por causa dos outros dois (que faleceram), a gente só tem esse agora." (M7)

"Tenho muito medo agora, assim, deles na rua." (M8)

"A gente não sabe se amanhã as pessoas que amamos vão estar aqui.” (I2)

Quanto às circunstâncias ambientais relativas ao homicídio, uma família (F8) relatou medo de permanecer morando no mesmo local, uma vez que o perpetrador do homicídio residia nas proximidades e ainda não havia sido preso. A possibilidade de receber retaliações era o principal receio: "Passei 13 dias na casa da minha tia, fiquei com medo de ir pra casa. [...] Dele (perpetrador do homicídio) fazer alguma coisa com meus filhos... Que ele esqueça a gente e deixa meus filhos em paz" (M8).

Outra razão expressa pelos participantes para querer evitar o local de moradia se referiu às lembranças do jovem falecido. Três famílias (F2, F3 e F5) admitiram não suportar conviver com as recordações. Para duas delas (F2 e F5), os homicídios estavam relacionados às circunstâncias contextuais ou à presença de violência na comunidade, como manifestado: "O problema é que foi aqui, na minha porta, praticamente, foi na esquina da minha rua" (M2). Para outra família (F3), o que a impedia de permanecer na mesma casa era o fato de não querer ficar sozinha na propriedade: "Eu não aceito ficar lá sem meu filho, sem nada, entendeu?" (M3).

\section{Mudanças Familiares e Sociais}

As mudanças ocorridas nas famílias após a morte do jovem foram tanto negativas como positivas, embora com prevalência das primeiras. Dentre as mudanças positivas, ênfase foi dada ao aprimoramento dos recursos pessoais, justamente pelas famílias (F1, F2 e F7) que haviam enfrentado a morte de outro jovem, nas mesmas circunstâncias. As verbalizações, a seguir, ilustram o aprendizado dos participantes com a experiência:

\footnotetext{
"Eu passei a me sentir uma pessoa melhor. Eu mudei o meu modo de vida, de pensar, passei a ser mais solidária para com as outras pessoas, a ver mais o próximo." (M2)

“Eu já aprendi a lidar com a situação." (M7)

"Aprendi a não brigar por pouca coisa. Abraçar quando sentir vontade de abraçar. Falar, o que tiver que ser dito, "eu te amo". Nunca deixar pra amanhã." (I1)
}

O crescimento no âmbito escolar e do trabalho também foi mencionado: "Agora eu tô trabalhando, tô estudando" (M3). Em contrapartida, as mesmas famílias que apontaram aspectos positivos (F1, F2, F7) relataram aspectos negativos referentes ao ritmo de sono e distúrbios no apetite (F1 e F2), declínio no rendimento acadêmico (F2) e alterações no comportamento social (F7).

\footnotetext{
"Minha vida era só deitar, dormir. Era chorar, todo dia, a noite toda." (M2)

"Eu não conseguia comer, nada tinha sabor. Não queria comer." (M1)
} 
"Minhas notas na escola baixaram. Não tava conseguindo me concentrar." (I2).

"Antes eu era o maior brincalhão. Agora raramente eu brinco aqui em casa." (I7)

No âmbito das mudanças ocorridas no grupo familiar, uma maior aproximação entre os membros foi destacada por duas delas (F1 e F8). Ambas já haviam avaliado suas famílias como unidas no período antecedente à morte, tendo sido a união reforçada a partir do evento. "A família se juntou mais, assim, ficou mais próxima" (M8). "A gente ficou mais ainda unida" (I1). Quanto aos aspectos negativos da família vista como um grupo foi destacado o distanciamento, a desestruturação e o vazio por parte de duas famílias (F2 e F7), conforme indicado pelas genitoras:

"Tento ir pra lá... me aproximar mais (da família extensa), mas quando eu vou e vejo que eles não vêm até aqui me ver, ai eu me afasto, sabe?" (M2)

"A casa ficou... sem graça, agora. Tipo, todo mundo ficava rindo aqui dentro de casa, brincava... minha mãe falando com ele (irmão), aí... agora nem... a casa fica calada...” (I7)

A morte do jovem mostrou-se perturbadora às relações dos casais, como ilustra a verbalização seguinte: "Ele (o marido) desequilibrou, ele queria voltar a beber de novo. Ele voltou a beber, bebeu umas duas vezes. A gente voltou a discutir" (M7). O distanciamento entre os casais foi mencionado por quatro famílias (F2, F4, F5 e F7), enquanto a aproximação foi mencionada apenas por uma família (F1). Além disto, em uma das famílias (F3), cuja genitora vivia só, sem companheiro ou outros filhos, ela optou por arrumar uma companhia: "Eu até arranjei um namorado... Arranjei um namorado aí... pra mim não ficar tão sozinha" (M3).

As relações parentais evidenciaram aproximação entre os genitores e seus outros filhos (F2 e F7). A este respeito, os participantes relataram: "Depois do acontecido, a relação (com os filhos) melhorou ainda mais, bem mais" (M2). "Minha mãe também começou a se preocupar com os meus estudos" (I7). De maneira similar, houve mudanças nas relações fraternais (F2): "Eu 'tô' evitando muito discutir (com os irmãos), gritar" (I2).

Também foram mencionadas alterações na divisão de tarefas domésticas. Em uma das famílias (F4), o jovem vitimado era filho único e, na outra (F6), a jovem falecida havia deixado dois dependentes, isto é, dois filhos pequenos, como mostram os exemplos: "Ele (o jovem) ajudava nós e aí não tem mais quem ajuda" (M4). "Com as crianças pequenas, eu tenho que trabalhar pra criar eles dois. Minha responsabilidade dobrou" (M6).

Com base nos dados apresentados quanto às mudanças familiares e sociais, percebe-se que não houve discrepância entre as respostas fornecidas pelos participantes do Grupo A e do Grupo B. Todavia, as famílias que já haviam perdido outro ente jovem em circunstâncias semelhantes relataram, de maneira mais veemente, mudanças positivas de caráter intrapessoal, como o aprimoramento de recursos pessoais.

Após a perda, o processo de enfrentamento de cada membro da família e de reorganização de todo o grupo familiar foi favorecido pela rede social de apoio, constituída tanto por pessoas da própria família como por vizinhos e amigos, conforme dados apresentados a seguir.

\section{Rede Social de Apoio}

No período subsequente ao homicídio, o apoio fornecido pela rede social das famílias mostrou-se relevante para o enfrentamento da morte do jovem, em ambos os Grupos. Quanto ao suporte oferecido por familiares, parte das famílias do Grupo A (F7 e F8) e todas do Grupo B (F1, F2 e F6) mencionaram ter sido acolhidas: "Minha família me ajuda, meu genro me ajuda. A minha família sempre do meu lado, me ajudando. Todo mundo me ajuda, não deixam faltar nada" (M6). Essas mesmas famílias (F1, F2, F6, F7 e F8) relataram ter recebido apoio de vizinhos, amigos e colegas de trabalho.

Uma família (F3) não tinha familiares próximos e não contava com uma rede familiar consistente, mas, mesmo assim, relatou ter sido amparada por pessoas da própria comunidade que, até então, não conhecia: "Eu recebia apoio, assim, na rua, sabe... as pessoas paravam comigo, conversavam comigo, abraçavam comigo" (M3). O apoio de instituições da comunidade, como igreja e escola, foi mencionado por participantes de apenas duas famílias (F1 e F7). A primeira (F1) relatou que representantes das duas instituições fizeram uma visita a eles; a outra (F7) apontou somente a igreja como provedora de suporte. Entretanto, todas as demais famílias (F2, F3, F4, F5, F6 e F8) relataram não ter recebido apoio por parte das instituições da comunidade.

Duas famílias do Grupo A (F4 e F5) disseram não ter recebido apoio algum, nem de parentes, amigos e tampouco de instituições; ao contrário, sentiram-se criticadas pelo que ocorreu: "Elas (irmãs) dizem assim... que eu teimei, que eu fui muito teimosa, porque eu podia ter mudado daqui" (M4). "Na hora que eu mais precisei, ninguém ficou do meu lado. Ninguém. Eu não vi apoio de ninguém" (M5).

No que tange à rede social, portanto, as famílias mais suscetíveis à falta de apoio foram as que pertenciam ao primeiro grupo (Grupo A), cujos jovens tinham algum comprometimento em ações delituosas. Pelos relatos das genitoras, a ausência desse suporte parece estar relacionada ao histórico da vítima e à fragilidade dos vínculos dos familiares com as instituições das comunidades às quais pertenciam.

\section{Discussão}

Devido às circunstâncias e motivações que envolvem os homicídios, o processo de luto dos familiares apresenta particularidades distintas às das mortes naturais. Eventos traumáticos como as mortes violentas costumam, em um primeiro momento, provocar estresse, angústia e busca pela pessoa falecida; depois, medo, agitação e vigilância excessiva, destinadas a evitar lembranças do acontecimento (Raphael et al., 2006). Por tratar-se de um ato intencional e deletério, suscita aos sobreviventes sentimentos de insegurança e medo quanto à própria vida (Raphael et al., 2006). Sendo assim, para lidar com o estresse, os indivíduos buscam descobrir em que medida há risco iminente e de que forma podem melhor se proteger. 
As pessoas que enfrentam mortes por homicídio, como as deste estudo, têm uma árdua tarefa no que se refere ao processo de luto, independentemente da história pregressa das vítimas. Mães e irmãos, tanto do Grupo A como do Grupo B, manifestaram a sensação de descontrole, desespero e perda da noção de realidade, seguidos por expressões de dor e sofrimento. Vontade de morrer, indiferença com a vida e saudade foram, também, descritos. De acordo com Spungen (1998), diante de circunstâncias e influências externas, advindas dos episódios, geralmente os familiares percebem a si próprios como impotentes, desprovidos do controle da situação e, portanto, mais suscetíveis a reações emocionais intempestivas e a mudanças.

A reação exacerbada e a ideação suicida são indicativas da necessidade de atendimento especializado (Murphy, 2006), pois, quando um filho morre, uma parte significativa da energia vital dos pais pode, efetivamente, morrer também (Schaefer \& Moss, 2007), desencadeando emoções avassaladoras e impulsos autodestrutivos. Duas genitoras, por exemplo, referiram ter pensado em cometer suicídio e ter tomado providências para consolidar o ato.

Dependendo das condições que envolvem a perda, da história pregressa familiar e, sobretudo, das situações ambíguas quanto à morte, sentimentos de raiva e de culpa podem predominar no luto (Malone, 2007). Quanto a esse último sentimento, somente as genitoras do Grupo A descreveram a sensação de fracasso diante das adversidades que antecederam os homicídios. Provavelmente essa percepção tenha contribuído para uma autoavaliação negativa das participantes, tornando as críticas dos demais membros da família às suas atitudes ainda mais contundentes.

As reações de vingança e revolta também fizeram parte do repertório emocional das famílias pertencentes a ambos os grupos. Porém, essas reações foram direcionadas a alvos distintos. Em uma das famílias do Grupo A, por exemplo, foi expresso o desejo de vingança direcionado a parentes, vizinhos e conhecidos, em função do escasso apoio recebido quando o jovem estava vivo e passava por dificuldades. A experiência de desamparo pode ter aumentado as fantasias retaliativas desses sobreviventes, cujos pensamentos de revanche não se destinavam somente ao perpetrador do homicídio ou a Deus, como nas famílias do Grupo B, mas também às pessoas da sua rede social.

As ideias de revidar ou infligir aos outros o mesmo tipo de dano são comuns, embora dificilmente se transformem em ações concretas (Spungen, 1998), sendo mais encontradas no sistema fraternal (Temple, 1997). Nessas situações, as crenças e a fé têm um papel importante e são costumeiramente reavaliadas e colocadas à prova (Walsh, 2007). Por outro lado, quando a morte é interpretada como um castigo, a pessoa passa a acreditar que é punida por algo que fez ou que deixou de fazer, conforme apontado por duas genitoras. A primeira, do Grupo A, compreendia que tinha falhado na educação do jovem; enquanto a segunda, do Grupo B, dizia estar sendo castigada pelo fato de ter cuidado de um sobrinho que, envolvido em atos de delinquência, havia morrido de maneira similar. Isto é, mesmo pertencendo a Grupos diferentes, as duas participantes expressaram frustração quanto ao papel de cuidadoras. Conforme apontam Raphael et al. (2006), afetos dessa natureza se dirigem tanto às pessoas ligadas às vítimas, como às instâncias macrossociais, que foram incapazes de impedir o homicídio.

Quando todas estas reações são compreendidas como parte de um processo adaptativo, sem o viés patológico, a pessoa consegue reconhecer, lidar e aceitar seus afetos sem o temor de ser julgada como enferma (Spungen, 1998). Tal postura auxilia na restauração e na retomada da trajetória dos indivíduos. No entanto, é preciso ter em mente que as mortes juvenis constituem acontecimentos não normativos, capazes de ocasionar comportamentos disfuncionais, seja no âmbito do desenvolvimento individual, seja no âmbito familiar (Walsh \& McGoldrick, 2004).

Nessa última esfera, a do desenvolvimento familiar, as principais mudanças apontadas pelas famílias referiram-se às relações amorosas e conjugais. Das cinco famílias de ambos os Grupos, cujos genitores eram casados ou tinham relacionamento íntimo, apenas uma relatou o fortalecimento do vínculo entre os parceiros. As demais informaram distanciamento nas relações afetivas com o cônjuge/namorado. Isso evidencia que a morte de uma criança ou jovem tende a aumentar a chance de distúrbios e disfunções no relacionamento conjugal. Portanto, os rompimentos ou divórcio não são decisões infrequentes entre casais que sofrem a perda de um filho (Spungen, 1998).

As famílias do estudo apresentaram especificidades quanto à experiência anterior de perda, dentre as quais, a intensa dificuldade em conciliar o sono, a falta de apetite, as mudanças de comportamento e as alterações de humor, conforme relato tanto das mães quanto dos irmãos. Ainda que a maioria consiga dar prosseguimento às suas vidas, parte dos sobreviventes poderá apresentar sinais de estresse crônico (Shear et al., 2006), tendo em vista que a perda abrupta de alguém significativo é um evento perturbador que provoca mudanças em distintos níveis (Walsh, 2007), sobretudo para aqueles que, pela segunda vez, lidam com um episódio desse tipo.

Em contrapartida, as famílias que sofreram a segunda perda por homicídio foram também as que expressaram alterações positivas intrapessoais e interpessoais, após o episódio. Mesmo eventos trágicos, como as mortes violentas, podem oportunizar crescimento e transformações (Bonanno, 2006), reordenando prioridades e estabelecendo novas concepções de mundo (Armour, 2006). O aumento da empatia, da solidariedade no contexto intra e extrafamiliar das famílias deste estudo, a expressão de sentimentos afetuosos e a aproximação com os filhos e entre os irmãos, provavelmente se originaram de uma reavaliação dos valores, condutas e estilos de comunicação. O respeito mútuo, o uso de estratégias eficazes de enfrentamento e o encorajamento entre os membros da família facilitam a manutenção da estabilidade e o reordenamento das prioridades (Salloum \& Rynearson, 2006).

Ainda que a qualidade das relações afetivas, a coesão, a segurança e a ausência de discórdias significativas no grupo familiar constituam importantes fatores de proteção para o desenvolvimento de competências e habilidades sociais (Dessen \& Polonia, 2007), bem como para a superação de adversidades, estes não parecem ser os únicos fatores. Há outros aspectos contextuais relativos aos homicídios que precisam ser levados em conta. Por exemplo, os relatos apontaram a 
necessidade de os sobreviventes mudarem para outros locais de moradia, o que gerou uma transformação ainda mais profunda na trajetória do grupo familiar. Os motivos alegados disseram respeito ao temor dos sobreviventes de permanecerem na comunidade devido à violência e à incapacidade para lidarem com as lembranças do jovem ou do episódio. $\mathrm{O}$ primeiro motivo está relacionado à falta de segurança e de proteção das famílias por parte do Estado, principalmente pelo fato do perpetrador do homicídio residir nas redondezas ou encontrar-se em liberdade; o segundo refere-se às dificuldades dos familiares decorrentes das lembranças do jovem na residência ou das recordações do evento.

As consequências da violência representadas pelas migrações são, assim, uma violação aos direitos humanos, como ressaltam Builes et al. (2008) e tornam a família mais suscetível a rupturas e a perturbações no seu modo de organização (Mota et al., 1999). Neste sentido, a rede social de apoio desempenha um papel fundamental na reestruturação dos sobreviventes, tanto construindo novos laços de afeto como fortalecendo e até resgatando antigos contatos (Schaefer \& Moss, 2007).

Em situações extremas, como mortes violentas, moradores das proximidades e vizinhos podem se mobilizar para oferecer ajuda e agregar conexões à rede social de apoio, pois as dificuldades para arcar com gastos emergenciais, como despesas com o funeral e as demais cerimônias, são frequentes. Embora essa seja uma situação adicional de tensão que pode abalar a organização financeira da família (Asaro, 2001), os relatos apontam para a superação desse obstáculo, na medida em que as famílias contam com a ajuda de parentes, amigos e vizinhos.

A estrutura e as funções da rede social variam de acordo com o contexto e com o tempo histórico (Dessen \& Braz, 2000) e, dependendo de suas condições, intensificam a fragilidade do sistema familiar. Quando os sobreviventes apresentam um número limitado de pessoas em sua rede, o acolhimento ofertado por pessoas estranhas e desconhecidas mostra-se um suporte importante no período do luto. Sendo assim, a participação efetiva do indivíduo na comunidade o predispõe a lidar com as mudanças, favorecendo o seu entrosamento com as pessoas e os recursos disponíveis no contexto social (Andrade \& Vaitsman, 2002).

Instituições, representantes de classe e do sistema de saúde, bem como líderes comunitários constituem fontes significativas de ajuda aos enlutados (Raphael et al., 2006) e, como tal, deveriam ser mais incentivadas. Para as famílias participantes deste estudo, entretanto, as instituições da comunidade (igreja e escola) tiveram uma pequena atuação, o que demonstra a fragilidade, ou mesmo ausência de vínculos entre os sobreviventes e as organizações públicas. A rede de apoio institucional deveria ser capaz de oferecer assistência legal, psicológica e financeira aos enlutados (Viano, 2007), especialmente aos oriundos de classe socioeconômica menos favorecidas, que não dispõem de recursos. Essas famílias merecem um olhar diferenciado, do ponto de vista da saúde pública.

$\mathrm{O}$ reajustamento derivado da morte de um ente querido constitui um processo que implica mudança de papéis e comportamentos, afetando inclusive os contatos estabelecidos fora do círculo das famílias (Bromberg, 1996; Schaefer \& Moss, 2007). Embora elas sejam apenas uma das vertentes do problema, frequentemente, não são consideradas como vítimas de um ato criminoso (Armour, 2002; Spungen, 1998). No entanto, as inúmeras demandas que o homicídio ocasiona afetam as relações entre irmãos, avós, tios e primos, dependendo do grau de afinidade e proximidade que eles tinham com a vítima (Spungen, 1998), e são essas mesmas pessoas que, muitas vezes, têm de se mobilizar para desenvolver competências e lidar com as novas tarefas e compromissos derivados da perda.

Ademais, os familiares se acumulam no sistema público de saúde, nas filas de atendimento psicossocial, nas esquinas das comunidades em que moram, por falta de prioridade das instituições governamentais à população atingida por atos criminosos. Para atender à demanda, algumas modestas iniciativas têm sido instituídas, direcionadas a tratar pessoas vitimadas pela violência (Viano, 2007). Contudo, quase inexistem programas específicos aos sobreviventes de homicídio, cuja invisibilidade compromete a saúde física e mental, a capacidade laboral, a expectativa de vida e a visão de um futuro melhor (Armour, 2006). É importante que se considere as mudanças na qualidade das relações, nas possibilidades de crescimento e continuidade das trajetórias dos sobreviventes, após eventos de morte violenta.

Por tratar-se de um fenômeno complexo, que perpassa as desigualdades na distribuição de renda e questões sociais e culturais (Waiselfisz, 2010), a violência homicida juvenil exige a construção de ações, tanto no sentido de poupar vidas quanto de auxiliar as pessoas enlutadas a enfrentar a perda. No que tange à prevenção, a variedade de fatores implicados e a escassez de trabalhos na área dificultam a compreensão dos episódios de homicídio e, por conseguinte, a implantação de programas efetivos (Cano \& Ribeiro, 2007). Está claro, entretanto, que sem investimentos em pesquisas científicas (Armour, 2002, 2006) e em políticas públicas dirigidas aos jovens e suas famílias, poucas mudanças serão, de fato, possíveis.

\section{Referências}

Andrade, G. R. B., \& Vaitsman, J. (2002). Apoio social e redes: Conectando solidariedade e saúde. Ciência \& Saúde Coletiva, 4, 925-934.

Armour, M. P. (2002). Journey of family members of homicide victims: A qualitative study of their post-homicide experience. American Journal of Orthopsychiatry, 72, 372-382.

Armour, M. P. (2006). Meaning making of survivors of violent death. In E. K. Rynearson (Ed.), Violent death: Resilience and intervention beyond the crisis (pp. 101-122). New York: Routledge.

Asaro, M. R. (2001). Working with adult homicide survivors, part I: Impact and sequelae of murder. Perspectives in Psychiatric Care, 37, 95- 101.

Barber-Madden, R., \& Saber, B. A. (2010). A situação dos jovens no mundo. In R. Barber-Madden \& T. F. Santos (Eds.), A juventude brasileira no contexto atual e em cenário futuro (pp. 17-39). Brasília: UNFPA.

Bardin, L. (1977). Análise de conteúdo. Lisboa: Edições 70.

Bonanno, G. A. (2006). Grief, trauma, and resilience. In E. K. Rynearson (Ed.), Violent death: Resilience and intervention beyond the crisis (pp. 31-46). New York: Routledge. 
Bromberg, M. H. P. F. (1996). Luto: a morte do outro em si. In M. H. P. F. Bromberg, M. J. Kovács, M. M. J. Carvalho, \& V. A. Carvalho (Eds.), Vida e morte: Laços de existência (pp. 98121). São Paulo: Casa do Psicólogo.

Builes, G. M. G., Arias, G. M. A., \& Minayo, M. C. (2008). Las migraciones forzadas por la violencia: El caso de Colombia. Ciência \& Saúde Coletiva, 13, 1649-1660.

Cano, I., \& Ribeiro, E. (2007). Homicídios no Rio de Janeiro e no Brasil: Dados, políticas públicas e perspectivas. In M. V. G. Cruz \& E. C. Batitucci (Eds.), Homicídios no Brasil (pp. 5178). Rio de Janeiro: FGV.

Currier, J. M., \& Neimeyer, R. A. (2006). Fragmented stories: The narrative integration of violent loss. In E. K. Rynearson (Ed.), Violent death: Resilience and intervention beyond the crisis (pp. 85-100). New York: Routledge.

Dessen, M. A. (2009). Questionário de caracterização do sistema familiar. In L. Weber \& M. A. Dessen (Eds.), Pesquisando a família: Instrumentos para coleta e analise de dados (pp. 102-114). Curitiba: Juruá.

Dessen, M. A., \& Braz, M. P. (2000). Rede social de apoio durante transições familiares decorrentes do nascimento de filhos. Psicologia: Teoria \& Pesquisa, 16, 221-231.

Dessen, M. A., \& Cerqueira-Silva, S. (2009). Desenvolvendo sistemas de categorias com dados de entrevistas. In L. Weber \& M. A. Dessen (Eds.), Pesquisando a família: Instrumentos para coleta e análise de dados (pp. 43-56). Curitiba: Juruá.

Dessen, M. A., \& Polonia, A. C. (2007). A família e a escola como contextos de desenvolvimento humano. Cadernos de Psicologia e Educação Paidéia, 17, 21-32.

Domingues, D. F., Villas Boas, A. C. B. V., \& Dessen, M. A. (2011). Homicídio juvenil por arma de fogo e reorganização familiar: um estudo de caso. PSICO (PUCRS), 42, 51-58.

Elgar, F. J., \& Aitken, N. (2010). Income inequality, trust and homicide in 33 countries. The European Journal of Public Health, 4, 1-6.

Kovács, M. J. (1992). Morte e desenvolvimento humano. São Paulo: Casa do Psicólogo.

Malone, L. (2007). In the aftermath: Listening to people bereaved by homicide. Probation Journal, 4, 383-393.

Mayer, L. R. (2002). Rede de apoio social e representação mental das relações de apego de meninas vítimas de violência doméstica. Tese de Doutorado, Universidade Federal do Rio Grande do Sul, Porto Alegre.

Miller, L. (2009). Family survivors of homicide: Symptoms, syndromes, and reaction patterns. The American Journal of Family Therapy, 37, 67-79.

Mota, E. L. A., Franco, A. L. S., \& Motta, M. C. (1999). Migração, estresse e fatores psicossociais na determinação da saúde da criança. Psicologia: Reflexão e Crítica, 12, 28-42.

Murphy, S. A. (2006). Evidence-based interventions for parents following their children's violent death. In E. K. Rynearson (Ed.), Violent death: Resilience and intervention beyond the crisis (pp. 175-194). New York: Routledge.

Peres, M. F. T. (2007). Homicídios, risco e vulnerabilidade: para uma discussão da dinâmica da vitimização por homicídios. In M. V. Gonçalves-Cruz \& E. C. Batitucci (Eds.), Homicídios no Brasil (pp. 125-139). Rio de Janeiro: FGV.
Peres, M. F. T., Cardia, N., \& Santos, P. C. (2006). Homicídios de crianças e jovens no Brasil: 1980-2002 (Relatório Institucional, s.n.). Retrieved from http:www.neveusp.org

Pressman, D., \& Bonanno, G. A. (2007). With whom do we grief? Social and cultural determinants of grief processing in the United States and China. Journal of Social and Personal Relationships, 24, 729-746.

Raphael, B., Stevens, G., \& Dunsmore, J. (2006). Clinical theories of loss and grief. In E. K. Rynearson (Ed.), Violent death: Resilience and intervention beyond the crisis (pp. 3-29). New York: Routledge.

Salloum, A., \& Rynearson E. K. (2006). Family resilience after violent death. In E. K. Rynearson (Ed.), Violent death: Resilience and intervention beyond the crisis (pp. 47-63). New York: Routledge.

Schaefer, J. A., \& Moss, R. H. (2007). Bereavement experiences and personal growth. In M. S. Stroebe, R. O. Hansson, W. Stroebe, \& H. Schut (Eds.), Handbook of bereavement research: Consequences, coping, and care (5ed., pp. 145-167). Washington, DC: American Psychological Association.

Shear K., Gorscak, B., \& Simon, N. (2006). Treatment of complicated grief following violent death. In E. K. Rynearson (Ed.), Violent death: Resilience and intervention beyond the crisis (pp. 157-174). New York: Routledge.

Sluzki, C. E. (1997). A rede social na prática sistêmica. São Paulo: Casa do Psicólogo.

Spungen, D. (1998). Homicide: The hidden victims - a guide for professionals. London: Sage.

Temple, S. (1997). Treating inner-city families of homicide victims: A contextually oriented approach. Family Process, 36, 133-149.

Vasconcelos, A. M. N., \& Costa, A. (2005). Demografia da violência no Distrito Federal: evolução e características. In A. Paviani, I. C. B. Ferreira \& F. F. P. Barreto (Eds.), Brasília: Dimensões da violência urbana (pp. 33-56). Brasília: UnB.

Viano, E. C. (2007). Homicídio: uma perspectiva vitimológica. In M. V. Gonçalves-Cruz \& E. C. Batitucci (Eds.), Homicídios no Brasil (pp. 105-124). Rio de Janeiro: FGV.

Waiselfisz, J. J. (2010). Mapa da violência: Anatomia dos homicídios no Brasil. São Paulo: Instituto Sangari.

Walsh, F. (2007). Traumatic loss and major disasters: Strengthening family and community resilience. Family Process, 2, 207-227.

Walsh, F., \& McGoldrick, M. (2004). Loss and family: A systemic perspective. In F. Walsh \& M. McGoldrick (Eds.), Living beyond loss: Death in the family (2 ${ }^{\text {nd }}$ ed., pp. 3-26). New York: W.W. Norton \& Company.

Recebido em 26.12.2011

Primeira decisão editorial em 21.06.2012

Versão final em 01.08.2012

Aceito em 08.08.2012 